\title{
RESEARCH
}

Open Access

\section{The effect of Hallyu on tourism in Korea}

\author{
Eun-song Bae ${ }^{1}$, Meehyang Chang ${ }^{2}$, Eung-Suk Park ${ }^{3}$ and Dae-cheol Kim ${ }^{4 *}$
}

\author{
* Correspondence: \\ dckim@hanyang.ac.kr \\ ${ }^{4}$ School of Business, Hanyang \\ University, Seoul, Korea \\ Full list of author information is \\ available at the end of the article
}

\begin{abstract}
The purposes of the study are to estimate inbound tourism demand and to analyze the effect of the Korean Wave and Economic indicators on it. For these purposes, we examined the influence of Korean Wave, GDP, CPI and exchange rate on inbound tourism demand for foreign tourists from the USA, China, Japan and Hong Kong to Korea. In order to measure the Korean wave, the export amount of Hallyu related contents exported to each of the four countries is used. GDP means the GDP of each of the four countries. However, the CPI and the exchange rate are relative to Korea. Penal data on tourism demand, Korean Wave, and Economic indicators from 1997 to 2014 are collected for analysis. Through the various tests for panel analysis model selection, the best fit model proved to be a random effect model. As a result, Korean Wave, GDP, and exchange rate have a statistically significant impact on tourism demand. Therefore, it can be seen that the Korean Wave is one of the important factors for attracting foreign tourists to Korea in four countries. Also, the results show that overseas tourism increases when the economic income of the country is high and the exchange rate is favorable. However, CPI does not appear to have a statistically significant impact on tourism demand. This indicates that tourists are not overly concerned about the cost of the travel country when planning a trip.
\end{abstract}

Keywords: Hallyu (Korean wave), Tourism demand, Panel data analysis

\section{Introduction}

Korean Wave is a term originally used by Chinese media in 1999. It refers to the phenomenon that young people in China are enthusiastic about Korean popular culture such as Korean dramas and popular songs. It is also defined as the phenomenon that Korean pop culture is spreading overseas or Korean pop culture is gaining popularity in global market (Lee, 2011; Jang et al., 2016). Recently, the Korean Wave is led by music such as K-pop, and visual media represented by drama and broadcasting.

The Korean Wave has various economic effects and cultural ripple effects. In 2014, the content export of the music industry increased $21.0 \%$ compared to the previous year, and the average annual increase rate of K-POP was $41.7 \%$. In addition, total content exports amounted to US \$ 5273.32 million with an annual average increase of 13.4\% from 2010 to 2014 (Chae, 2014).

In addition, Korean Wave content has a great influence on the image formation of Korea to foreigners (Lee, 2011; Lee \& Workman, 2015), and the improved national brand value is linked to promotion of purchase of Korean products abroad (Chae, 2010). The Korean Wave is spreading across all industries and causing the Korean Wave effect.

(c) The Author(s). 2017 Open Access This article is distributed under the terms of the Creative Commons Attribution 4.0 International License (http://creativecommons.org/licenses/by/4.0/), which permits unrestricted use, distribution, and reproduction in any medium, provided you give appropriate credit to the original author(s) and the source, provide a link to the Creative Commons license, and indicate if changes were made. 
Especially, medical tourism (cosmetic), cosmetics industry and beauty industry are directly affected by the Korean Wave. Fashion and style products, which are closely related to Hallyu stars, are selling in Asia, where Hallyu are influential, such as China and Southeast Asia. In the cosmetic industry, Korean stars are used as marketing points to gain the image and high reputation of leading the latest trends. (Chae, 2014; Yun, 2015; Witt, 2017).

As the interest of Korea increases due to the influence of the Korean Wave, the number of foreigners visiting Korea is increasing. The number of foreign tourists visiting Korea has increased nearly fourfold from 300,000 in 1998, when the Korean Wave began, to 11.8 million in 2014. Of the total number of foreign tourists, Asian accounted for $71.3 \%$ in 1998 and 83.5\% in 2014, indicating that the proportion of Asia, the center of the Korean Wave, has increased.

In particular, the United States, China, Japan, and Hong Kong account for more than $70 \%$ of the number of foreign tourists entering Korea. The proportion of Chinese tourists was only $4.96 \%$ of total tourists in 1998, when diplomatic relations were established with Korea, but it increased to 6.12 million in 2014, accounting for $43.14 \%$ of the total. Despite Japan's great earthquake that occurred in March 2011, Japan had a total of 3.28 million visitors, an $8.8 \%$ increase from the previous year, which accounted for $33.6 \%$ of total inbound travelers to Korea, followed by China with the largest number of tourists. As such, the number of foreign tourists visiting Korea is on the rise, and estimating and predicting tourist demand is the most important and fundamental task of looking at the present and future of tourism industry (Kim, 2014a, b).

Therefore, studies on tourism demand have been carried out steadily. The main determinants of tourism demand are the income and the price (Lee et al., 1996; Uysal, 1998; Quayson and Var, 1982; Qu \& Lam, 1997). Most studies also used the exchange rate, gross domestic product (GDP), international oil prices, and consumer price index (CPI) to measure income and prices. However, the study of Ko (2012) focuses on the Korean Wave as the cause of the increase of foreign tourists. In addition, according to Lee (2011), the number of foreign tourists entering Korea due to the influence of Korean Wave is increasing proportionally. However, it is hard to find any research that has proven the fact that Korean Wave is the cause of tourism demand. One reason for this is that it is difficult to quantify the ripple effect of the Korean Wave or its range. In this study, we used the export volume of Korean Wave content to measure Korean Wave to forecast tourism demand. In addition, tourists targeted for tourism demand forecasts were limited to China, Japan, USA and Hong Kong. As mentioned above, these four countries have the largest number of foreign tourists entering Korea and account for more than $70 \%$ of the total number of arrivals. Therefore, in this study, the determinants of tourism demand include not only the prices and incomes utilized in the prior studies, but also the Korean wave. As a research method, we want to use panel analysis method which reflects time series dynamic characteristics and the relationship between cross - sectional variables at the same time. This study examines the influence of Korean Wave, income, and prices on the demand for inbound tourism to Korea.

The research questions of the study are as followings: (1) What is the effect of Hallyu on Korean tourism demand? (2) Does GDP give an impact on inbound Korean tourism demand? (3) Is the CPI the factor that affect Korean tourism 
demand from foreign countries? (4) Does the currency exchange rate have an effect on inbound Korean tourism demand from foreign countries?

\section{Theoretical background}

\section{Tourism forecasting}

Demand forecasting has the purpose of estimating future demand based on past data (Joun, 2003). Tourism demand forecasting is a very important tool for planning and decision making at national and enterprise level (Tuner \& Witt, 2001). Therefore, conducting accurate demand forecasts helps minimize management risks and losses, and ultimately improves profitability, in order to help management decisions and manage the future efficiently (Song \& Witt, 2003). The accuracy of forecasting can be improved by establishing a suitable tourism demand forecasting model.

Various studies have been conducted to predict accurate and effective tourism demand. Demand forecasting in the tourism industry is mostly based on causal model predictions and time series forecasting, which are representative quantitative methods. The time series prediction method is a method to predict the future by analyzing patterns and trends based on accumulated data from the past over time. The model using the long-term equilibrium relation between the time series variables is representative of the time series prediction method. In order to predict the future through the past data, it is frequently used in the forecasting of tourism demand. However, there are limitations on the method of determining the determinants of tourism demand (Song \& Witt, 2006; Mo, 2009; Kim, 2014a, b). The causal model prediction method explores the relationship between tourism demand and decision variables, but disadvantage is that it only estimates static relationships at specific time points (Kim, 2014a). In order to solve this shortcoming, panel data analysis method is predominantly used in predicting tourism demand in recent years.

\section{Hallyu (Korean wave)}

Korea Tourism Organization (2012) defines Korean Wave as "a favorite phenomenon of Korean popular culture abroad". The Korean Wave has a multifaceted nature of cultural phenomena and economic phenomena, and is thus defined in a variety of ways because of its different viewpoints. As for the economic effects of the Korean Wave, the content export effect, the export effect of other industries, and the tourism effect are shown, and the economic ripple effect can be expected from this (Lee, 2011).

'Hallyu tourism' means that foreigners visit Korea and visit Hallyu tourist attractions due to the influence of this Korean wave. In the mid-1990s, Korean dramas attracted Japanese interest, and this interest is the starting point for the Korean Wave tourism that Japanese people visited Korea and visited the drama shooting location (Lee, 2011). Hallyu tourism is divided into broad meaning and narrow meaning depending on the activities of tourists. Narrow Korean wave tourism means tourism that participates in tourism activities directly related to Korean Wave, such as foreign tourists who are interested in Korean Wave, visiting film and drama shooting sites, participating in meetings with fans, and participating in performances related to K-Pop. In the broad sense of Korean Wave tourism, foreign tourists who visit Korea do not participate in tourism activities directly related to Korean Wave, but their direct reason for visiting Korea is their interest in Korean Wave. In a similar vein, films 
from the United States and Australia show attractive tourism incentives. In other words, the film has become a fascinating tourist attraction. The viewer who watched the movie has an interest in the country where the movie was made, so that the viewer of the movie is now turned into a tourist and visits the country. This is generally called movie tourism and has long been recognized as one of the factors that enhance tourism attractiveness (Ko, 2009). Film tourism, or film-induced tourism, is defined as a business that attracts visitors through stories associated with scenes and locations of places that appear in movies, dramas, music, and so on. In summary, it refers to the commercialization of set and shooting sites in connection with movies and dramas. Film tourism is one of the modern cultural tourism, and it is an important tourist product (Ko, 2009).

According to Mintel (2003), one in five tourists visiting the UK found Britain inspired by British television programs and movies, and 50\% of those who visited Scotland chose Scotland as their summer resort by Scottish TV dramas and movies. In New Zealand, the number of foreign tourists increased by an annual average of $5.6 \%$ after the opening of the movie 'The Lord of the Rings' in 2001, and 9\% of tourists were affected by the movie (Mintel, 2003). Although the perception of movie tourism is quite widespread, recently tourism agencies are making marketing efforts to profit by utilizing movie tourism, such as making videos or film maps to attract tourists (Riley \& Dorenl, 1992). However, in the tourism sector, efforts to identify the effects of such movies on the number of tourists or tourism income were insufficient compared to other industries.

In Korea, the number of tourists is increasing due to the Korean Wave. As an example, the number of Japanese tourists who visited Korea in 2004 after broadcasting the Korean drama "Winter Sonata" in Japan NHK increased by $35.5 \%$ compared to 2003. According to the Korea Tourism Organization (KTO) survey in $2004,47 \%$ of the respondents answered that they had visited Korea due to the influence of Korean drama. Due to the popularity of TV dramas such as Daejanggum, Autumn Fairy Tale, and Winter Sonata, the Korean Wave craze has led to Korean Wave tourism. As the Korean Wave has been reorganized into K-pop in dramas according to the times, there is an increasing number of Korean wave tourists entering Korea to watch K-pop concerts. In addition to raising awareness of Korea due to Korean Wave such as drama and K-pop, interest in Korean food, cosmetics, fashion, Korean language learning and Korean culture is also increasing. This leads to K-pop concerts, concert tours, shopping, language training and cultural tourism through visits to Korea. The popularity of Korean Wave and the number of foreign tourists are rapidly increasing. The genre of Korean Wave has also been diversified from drama to K-Pop, broadcasting programs, online games, performances and movies. Due to the influence of the Korean wave, Korea's export of large-scale cultural contents (movies, broadcast programs, games) has grown by more than 40\% every year since 2001 .

In the study of Song \& Song (2006), the origin of Korean wave tour is said to be popular culture content. Ko (2012) also addressed that Korean wave is formed through Korean popular culture content and is closely related to content competitiveness. Therefore, it can be interpreted that the extent to which Korean pop culture content is exported depends on the degree of competitiveness of Korean pop culture in exporting countries.

As we have seen above, in the case of existing Hallyu-related researches, most of them use the questionnaire to try to find out the visitor's revisit intention to Korea or 
the image of the Korean wave. Thus, the research using panel data on the influence of Korean Wave on tourism demand is insufficient. Therefore, a prediction model of how the Korean Wave in China, America, Japan and Hong Kong affects Korea 's tourism demand is needed.

\section{Other predictors (income, customer price index, currency exchanege rate)}

In the study of domestic and foreign research on the determinants of international tourism demand, the most important determinant of tourism demand is 'income' ( $\mathrm{Qu}$ \& Lam, 1997; Park 2009a, b; Song \& Song, 2006). In addition, most previous studies use GDP or per capita GDP as proxy variables to measure income (Lim, 1997). Consumer prices were also analyzed as an important determinant of tourism demand (Lee et al., 1996). According to economic theory, demand and price are inversely related if other conditions are constant. Therefore, the higher the price of tourism products and services in the target countries, the more likely the tourism demand will decrease (Song \& Song, 2006). Most of the previous studies have used the CPI as a proxy for travel prices. In relation to prices affecting tourist demand, the exchange rate affects the price level of a tourist country, and tourists are more aware of exchange rate fluctuations than price fluctuations. There are also a number of studies that have explored the importance of exchange rates in this respect (Uysal, 1998; Mo, 2010; Park, 2009a, b). In terms of the determinants of international tourism demand, the exchange rate is included as part of the travel price (Mo, 2004; Song \& Song, 2006) or is used as a separate independent variable (Lim, 1997; Park, 2009a, b; Mo, 2010). Kim (2011) used the exchange rate against the dollar in the study of the economic ripple effects on tourism demand, and Kim (2014b) and Kim (2014a) used the annualized exchange rate against the won.

\section{Methodology}

Data collection and operational definition of variables

The purpose of this study is to estimate the demand for inbound tourists entering Korea and to examine the factors influencing tourism demand. The data used are the panel data for 18 years from 1997 to 2014. The target countries of the demand forecasting model are China, Japan, USA, and Hong Kong with the largest number of foreign tourists entering Korea. These four countries account for more than $70 \%$ of the total number of foreign tourists visiting Korea in 2014. Table 1 below shows the definitions and sources of variables used in this study. panel data for 18 years from 1997 to 2014.

\section{Measures (research model)}

In this study, panel data and STATA 13 program are used for panel data analysis. The mathematical model of the estimates for inbound tourism demand is as follows.

$$
\begin{aligned}
\text { Inbound }_{i t}= & \alpha+\beta_{1} \text { Hallyu }_{i t}+\beta_{2} G D P_{i t}+\beta_{3} C P I_{i t}+\beta_{4} \text { Exchage Rate }_{i t} \\
& +\epsilon_{i t}(i=\text { USA, China, Japan and Hong Kong } ; t=1997, \ldots, 2014)
\end{aligned}
$$

The dependent variable of [1] is the number of tourists visiting Kore from each country $i$ of USA, China, Japan, and Hong Kong at time $t$. The explanatory variable, Hally $_{i t}$, means the amount of Korean Wave content exported to the country of $i$ at 
Table 1 Operational Definition of Variables

\begin{tabular}{llll}
\hline Variables & Unit & Describe Variables & Reference \\
\hline $\begin{array}{l}\text { Inbound Tourism } \\
\text { Demand }\end{array}$ & People & $\begin{array}{l}\text { Number of travelers to Korea from USA, } \\
\text { China, Japan and Hong Kong by year }\end{array}$ & The Bank of Korea (2016a, b) \\
$\begin{array}{l}\text { Hallyu (Korean } \\
\text { wave) }\end{array}$ & US $\$$ & $\begin{array}{l}\text { Amount of Hallyu contents exported to } \\
\text { USA, China, Japan, Hong Kong (by year) }\end{array}$ & Statistics Korea (2015) \\
GDP & US \$ & $\begin{array}{l}\text { Each country's (USA, China, Japan, Hong } \\
\text { Kong) GDP by year }\end{array}$ & World Bank (2016a, b) \\
$\begin{array}{l}\text { Customer Price } \\
\text { Index }\end{array} \quad$ Num, $(2010=100)$ & $\begin{array}{l}\text { Each country's (USA, China, Japan, Hong } \\
\text { Kong) relative CPI to Korea (by year) }\end{array}$ & World Bank (2016a, b) \\
Exchange Rate & KRW $\left(\begin{array}{l}\text { Korean Won exchange rates for each } \\
\text { country (Average rate by year) }\end{array}\right.$ & The Bank of Korea (2016a, b) \\
\hline
\end{tabular}

time $t$. In addition, $G D P_{i t}$ is the gross domestic product of $i$ at time $t$, and $C P I_{i t}$ is Korea 's CPI relative to $i$ ' s CPI at time $t$. And Exchage Rate Ex $_{i t}$ means the exchange rate of country $i$ against the Korean won at time $t$. $\alpha$ is the intercept, which means the individual characteristics of each individual country. And $\epsilon_{i t}$ means the error term.

\section{Hypotheses}

\section{Effect of Hallyu on tourism demand}

Due to the development of Korean Wave, there has been a change in the content of the Korean Wave, and the economic and cultural ripple effects of the Korean Wave are expanding into various fields and increasing in scale. One of the most prominent ripple effects, especially in the case of the Korean Wave, is tourism, and the number of inbound tourists is increasing rapidly. The beginning of this tendency is the increase of Japanese tourists due to the drama "Winter Sonata" in the 1990s. The flow of foreign tourists through the Korean Wave began to increase at the start of sightseeing in the scenic spot (Lee, 2011). In recent years, the influence of the Korean Wave has been growing more and more, as the Korean Wave, which was only focused on drama, expanded to entertainment and broadcasting formats. Therefore, in this study, the hypothesis was established that the tourism demand will increase as the influence of Korean Wave increases.

\section{H1: Hallyu(Korean Wave) has a positive effect on tourism demand for Korea.}

\section{Effect of other predictors on tourism demand}

Income is a variable with high explanatory power that affects tourism demand, and income is used as an independent variable in most research models. In addition, most of the proxy variables for measuring income are GDP or GDP per capita. If the national economy develops, it can lead to an increase in the national income, which means that there is more room for people to enjoy leisure life. As a result, the demand for the overseas travel of the people can be increased, and the demand for travel to Korea, which is growing due to the recent Korean wave, may increase. In this study, the following hypothesis was established by judging that tourism demand will increase if income increases.

H2: GDP has a positive effect on tourism demand for Korea.

Travel prices are used as an important explanatory variable in the determinants of international tourism demand. In previous researches, consumer price index is used as a proxy variable of travel prices in many studies. According to economic theory, 
demand and price are inversely related when other conditions are constant. Therefore, the higher the price of tourism products and services in the target country, the lower the demand for tourism would be (Song \& Song, 2006). That is, if the consumer price index is relatively higher than Korea, the travel price will be lowered, so the expenditure due to tourism can be increased. Therefore, when the consumer price index of each country is higher than that of Korea's CPI, it can be concluded that tourism demand will increase. Therefore, the following hypothesis is established.

\section{H3: CPI(compared to Korean CPI) has positive effect on tourism demand for Korea.}

The currency exchange rate is the exchange rate of each country against the Korean won. The impact of exchange rate on the determinants of international tourism demand is frequently mentioned (Mo, 2004; Song \& Song, 2006). The use of the exchange rate as an independent variable is based on the argument that tourists make tourist decisions based on exchange rates because they are more easily aware of exchange rate fluctuations than price changes (Witt \& Moutinho, 1995). In other words, if the exchange rate against the Korean won is high, the value of the country's currency will increase, so the burden of traveling abroad on travel to Korea can be reduced. On the contrary, if the exchange rate is lower than the Korean won against the Korean currency, Korea's KRW appreciation will lead to an increase in travel prices and a substantial rise in inflation, which can have a negative impact on tourism demand. Thus, the following hypothesis is proposed.

H4: Exchange Rate(Korean Won Currency) has a positive effect on tourism demand for Korea.

\section{Results}

\section{Descriptive statistics}

In this study, panel data was used to analyze the relationship between the Korean wave and economic indicators on tourism demand. The data used include tourism, inbound, hallyu, gross domestic product, consumer price index (CPI), and exchange rate (FX) against the Korean won for a total of 18 years from 1997 to 2014. The panel data of 4 countries including USA, China, Japan and Hong Kong are collected and 72 data are included for each variable. The descriptive statistics of the data can be summarized as in (Table 2). According to descriptive statistics for each variable, the average of tourism demand is 1.2 million, ranging from at least 96,000 to a maximum of 6.12 million. Broadcast content exports, a measure of Hallyu, averaged \$ 4.5 million, with a minimum of \$ 1.66 million and a maximum of \$ 174.55 million. The average GDP is \$ 6.41 trillion, ranging from $\$ 1.57$ trillion to $\$ 18$ trillion. The average CPI is 1.104 , the minimum value is 0.9291 , and the maximum value is 1.5621 . The average exchange rate

Table 2 Descriptive Statistics

\begin{tabular}{llllll}
\hline Variable & Obs & Mean & Std. Dev. & Min & Max \\
\hline Inbound & 72 & $1,209,112$ & $1,238,776$ & 96,650 & $6,126,865$ \\
Hallyu & 72 & $4,502,178.36$ & $3.96 e+07$ & $1,662,277$ & $174,554,033$ \\
GDP & 72 & $6.41 e+12$ & $5.59 e+12$ & $1.57 e+11$ & $1.80 \mathrm{e}+13$ \\
CPI & 72 & 1.104262 & 0.1468298 & 0.9291508 & 1.5621 \\
FX & 72 & 625.9186 & 493.9769 & 114.74 & 1413.14 \\
\hline
\end{tabular}


against the won is 625.9186 won, ranging from a minimum of 114.74 won to a maximum of 1413.14 won.

\section{Hypothesis test}

As a result of the model fit test to estimate tourism demand, the random effect model proved to be the most suitable. Table 3 shows the results of hypothesis testing on the impact of Korean Wave and economic indicators on tourism demand using the random effect model.

\section{Relationship between Hallyu and tourism demand}

The hypothesis about the effect of Hallyu on tourism demand was examined (H1). Hypothesis test result shows that the Hallyu has a significant effect on tourism demand at $1 \%$ significance level. The results of this research are similar to those of the existing Hallyu research. Oh (2005) investigated the influence of Korean wave on the reasons for visiting Korea. As a result, it was found that Korean Wave such as Korean TV dramas, songs, movies and performances had a great influence on the decision to travel to Korea. Yoo (2012) also examined the preference of tourism programs linked to the Korean wave content, and it was selected as the favorite program of star fan signage, drama filming, and performance product. In the study of Lee et al. (2006), the type of tourism related to Korean Wave such as Korean drama, tour with Hallyu star, sightseeing, concert, fan club were most important factors to decide to travel to Korea. As we have seen in the previous research, it was found that the influence of the Korean Wave through the Hallyu content has a great influence on the foreign tourists visiting the Korea.

\section{Relationship between other predictors and tourism demand}

The hypothesis on the effect of economic indicators on tourism demand was verified. The test result of Hypothesis $\mathrm{H} 2$ shows that GDP has a positive $(+)$ effect on tourism demand at a significance level of $1 \%(p$-value $=0.000)$. The result of tesing hypothesis $\mathrm{H} 3$ shows that the impact of CPI on tourism demand is not significant at a significance level of $10 \%$ (p-value $=0.172)$. For Hypothesis H4, the test result shows that the KRW-FX rate has a significant effect on tourism demand at a significance level of $1 \%$ ( $p$-value $=0.002$ ).

Although the economic indicators such as gross domestic product and exchange rate, which were mentioned in most researches on tourism demand, were found to have a significant effect on tourism demand, in this study, the CPI was found not to do. However, there are also some prior studies in which the CPI is not significant, and Kim (2014a)'s study is a good example. In his study, he estimated the number of tourists and the tourism income using explanatory variables such as GDP, CPI, exchange rate, and oil price. The results show that the exchange rate and the CPI are found to be significant variables in the number of tourists but the exchange rate and the price do not

Table 3 Estimation coefficient of tourism demand forecast by each model

\begin{tabular}{llll}
\hline Variable & Between Model & Fixed Model & Random Model \\
\hline Hallyu & -0.267213 & $0.0067744^{* * *}$ & $0.006693^{* * *}$ \\
GDP & $-4.60 \mathrm{e}-07$ & $2.82 \mathrm{e}-07^{* * *}$ & $2.79 \mathrm{e} 07^{* * *}$ \\
CPI & 0 & $-588,412$ & $-613,347.8$ \\
FX & $13,907.15$ & $1505.505^{* * *}$ & $1396.011^{* * *}$ \\
\hline
\end{tabular}

${ }^{* * *} p<0.01$ 
give direct influence on the tourism income. In the study of Kim (2014b), he estimated inbound tourist demand function and outbound tourist demand function using explanatory variables such as exchange rate, GDP, international oil price and CPI. The results show that for foreign tourists arriving in Korea, the price level of Korea had no effect on the foreign tourists, while Koreans were influenced by the price index of traveling countries when traveling abroad. He explains that the tourists from target countries of the UK, the US, China and Japan are not sensitive to Korea's prices because they are located in a higher economic position than Korea. On the other hand, most travelers are not as informed enough to compare their prices with Korean consumer prices. In addition, the difference in the exchange rate can be felt directly by the traveler (Witt \& Moutinho, 1995), but it can be said that the consumer price is relatively insensitive because it is difficult to compare. Therefore, the impact of inflation on tourism demand is not significant in this study.

\section{Conclusion}

In this study, the effects of the Korean Wave and economic indicators on inbound tourism demand of Korea is analyzed. For these, we examined the influence of Korean Wave, GDP, CPI and exchange rate on inbound tourism demand for foreign tourists from the USA, China, Japan and Hong Kong to Korea. Foreign tourists from these four countries account for more than $70 \%$ of Korea's tourist demand. Penal data on tourism demand, Korean Wave, and Economic indicators from 1997 to 2014 are collected for analysis. Through the various tests for panel analysis model selection, the best fit model proved to be a random effect model. The results of analyzing the influence of Korean Wave and economic indicators on tourism demand are summarized as follows.

First, the random effect model was adopted as the most suitable model for the study. Therefore, the random effect model was used to obtain the estimation result and to test the hypothesis. Second, Korean wave has a positive effect on inbound tourism demand. The increase in the export of Korean wave content used as a measure of Hallyu can be interpreted as an increase in the number of foreign tourists entering Korea. There needs to be a comprehensive and systematic tourism strategy that can attract a diverse foreign Korean fan base through the Korean wave, and it is necessary to develop various Korean wave content and strategies to spread the Korean wave. Especially, in order to revitalize Korean wave tourism, it is necessary to grasp the current situation and problems of Hallyu tourism accurately. Also, systematic research is needed to understand the tourism behaviors and customer requirements of the Hallyu fan base. That is, appropriate tourism activities and programs should be developed according to the trend of Korean Wave fans. For example, it is necessary to absorb Korean Wave fans by utilizing various contents such as Korean food, shopping, beauty, medical care, natural environment, fan meeting of Korean Wave tour, performance visit. In other words, it is necessary to encourage tourists to visit again or increase the number of stay days and to develop tourism programs and products for creating high added value.

Third, gross domestic product (GDP) of each country has a positive effect on inbound tourism demand. If the income increases, it can be interpreted that the demand for tourism is increasing because the extra money is increased and the burden on travel is reduced. 
Fourth, the exchange rate of Korean won against Korean won has influenced tourism demand. In the study of Witt and Witt (1995), tourists are more aware of exchange rate fluctuations than price changes, so that if the currencies of each country are higher than the won, the value of their currencies increases and the demand for oversess trip also increses.

Fifth, Korea's consumer price index does not affect tourism demand. In the study of Kim (2014a), it has been found that the price level of Korea does not affect theforeign tourist entering Korea. He explains that the tourists from target countries of the UK, the US, China and Japan are not sensitive to Korea's prices because they are located in a higher economic position than Korea. In addition, most travelers are not as informed enough to compare their prices with Korean consumer prices. In addition, the currency exchange rate can be felt directly by the traveler (Witt \& Witt, 1995), but the consumer price is relatively insensitive because of its difficulty in comparison. Therefore, the effect of inflation on tourism demand is not significant in this study.

Sixth, as the interest in Korea has increased due to the influence of the Korean Wave, the number of foreign tourists visiting Korea has increased. However, it is difficult to accurately calculate the influence of the Korean Wave on the tourism demand. Therefore, most of the studies have relied on the surveys of foreign tourists to estimate the effects of the Korean Wave. It is meaningful to study the development of the Korean wave scale and establish a model that can analyze the impact of Korean Wave on the inbound tourism demand, unlike the previous studies which utilized survey methods or trend comparison methods (Yun et al., 2016a, b).

This study has implications for research on the influence of Korean Wave and economic indicators on inbound tourism demand from China, USA, Japan and Hong Kong, but the following limitations exist.

First, we estimated the inbound tourism demand from foreign tourists of China, the US, Japan, and Hong Kong. However, if we increase the number of target countries, we can improve the accuracy of inbound tourism demand estimates. Secondly, it is meaningful to study the development of Hallyu contents export as a measure of Korean wave, but it is not a measure to explain Korean wave perfectly, and it has a limitation. Thus, more comprehensive scale should be developed for Hallyu.

In the case of Hallyu content export, the export target countries and export target contents are still concentrated in specific countries and specific fields. In particular, export destinations are heavily concentrated in China, Japan, the US, and Southeast Asian countries. For the development of Korean Wave and sustainable growth, it is necessary to reduce the concentration of Hallyu contents export and to develop a strategy for exporting various diverse contents. In addition, it will be possible to predict the demand more reliably by developing a Korean tourism demand model that includes more countries including Asia, Europe, Africa and the Middle East.

Acknowledgements

Not applicable.

Funding

Not applicable. 
Authors' contributions

EB developed and wrote the paper. MC mainly designed and performed panel data analysis. Sections 2 was mainly written by EP. DK developed concept and wrote the paper. All authors read and approved the final manuscript.

\section{Competing interests}

The authors declare that they have no competing interests.

\section{Publisher's Note}

Springer Nature remains neutral with regard to jurisdictional claims in published maps and institutional affiliations.

\section{Author details}

${ }^{1}$ Department of Business Administration, Hanyang University, Seoul, Korea. ${ }^{2}$ Sejong University, Seoul, Korea. ${ }^{3}$ Hanyang

University, Seoul, Korea. ${ }^{4}$ School of Business, Hanyang University, Seoul, Korea.

Received: 8 September 2017 Accepted: 30 October 2017

Published online: 10 November 2017

\section{References}

Chae, J. Y. (2010). Research on characteristics of the Japanese consumption of Korean pop culture: Centering on their consumption of Korean TV soap operas. Korean Journal of Consumer and Advertising Psychology, 11, 823-844.

Chae, J. Y. (2014), The need and composition of establishing Korean wave theme infrastructure, Korea Culture \& Tourism Institute.

Jang, Y. S., Ko, Y. J., \& Kim, S. Y. (2016). Cultural correlates of national innovative capacity: a cross-national analysis of national culture and innovation rates. JOltmC, 2, 23.

Joun, H. J. (2013). Tourism Forecasting, Korea Culture \& Tourism Institute.

Kim, H. J. (2011). Economical Spillover Effects of Television Content Exports on Tourism Demand to Korea, Journal of media economics \& culture, 9(4), 65-98.

Kim, H. J. (2014a). The study on tourism income forecasting by panel data analysis method. Journal of Tourism and Leisure Research, 26(2), 493-504.

Kim, S. T. (2014b). The study on tourism demand forecasting : Focused on panel data analysis method. Journal of Tourism and Leisure Research, 26(1), 115-129.

Ko, J. M. (2009), The Korean wave, beyond Asia and into the world, Korea Foundation international culture exchange.

Ko, J. M. (2012). The Korean wave culture and tourism. Korea Tourism Policy, 49, 33-40.

Korea Tourism Organization. (2012). Korea Statistical Report on Tourism Interim 2012, Oosgomunwha Sa.

Lee, W. H. (2011), A research on policy direction for Voluntourism, Korea Culture \& Tourism Institute.

Lee, S. H., \& Workman, J. E. (2015). Compulsive buying and branding phenomena. JOltmC, 1, 3.

Lee, C. K., Var, T., \& Blaine, T. W. (1996). Determinants of inbound tourist expenditures. Annals of Tourism Research, 23(3), 527-542.

Lee, C. K., Song, K. S., \& Song, H. J. (2006). Determinants of bi-national tourism demand from Japan to Korea: Using econometric models. Journal of Tourism \& Leisure Research, 11(18), 7-25.

Lim, C. (1997). An econometrics classification and review of international tourism demand models. Tourism Economics, 3(1), 69-81.

Mintel. (2003). Lord of the rings market research summary report. New Zealand: Tourism.

Mo, S. W. (2004). Korean inbound tourism as the comparative Disadvanaged goods. Tourism \& Leisure Research, $16(3), 27-44$

Mo, S. W. (2009). The short- and long-term effects of the changes of economic variables on the demand for and supply of tourism. Asia-Pacific Journal of Business \& Commerce, 9(1), 39-58.

Mo, S. W. (2010). The effects of exchange rate and oil price on tourism demand, Korea Academic Society of. Tourism Management, 24(6), 27-38.

Oh, C. O. (2005). The contribution of tourism development to economic growth in the Korean economy. Tourism Management, 26(1), 39-44.

Park H. M. (2009a), Linear regression models for panel data using SAS, Stata, LIMDEP, and SPSS, Indiana University, university information technology services.

Park, J. S. (2009b). Determinants of Japanese tourism demand for Korea. Journal of Tourism Sciences, 33(2), $287-302$.

Qu, H., \& Lam, S. (1997). A travel demand model for mainland Chinese tourists to Hong Kong. Tourism Management, 18(8), 593-597.

Quayson, J., \& Var, T. (1982). A tourism demand function for the Okanagan, BC. Tourism Management, 3(2), 108-115.

Riley, R. W., \& Doren, V. C. S. (1992). Movies as tourism promotion. A 'pull factor in a 'push' location. Tourism Management, 13(3), 267-274.

Song, K. S., \& Song, H. J. (2006). A study on the determinants of international tourism demand -focusing on Japanese tourist arrivals. Journal of Hospitality and Tourism Studies, 21, 112-127.

Song, H., \& Witt, S. F. (2003). Tourism forecasting: Accuracy of alternative econometric models. International Journal of Forecasting, 19(1), 123-141.

Song, H., \& Witt, S. F. (2006). Forecasting international tourist flows to Macau. Tourism Management, 27(2), 214-224.

Statistics Korea (2015), "Content Industry Statistics Survey" [Online], Korea Creative Content Agency, http://kosis.kr/index/ index.jsp, 2016/2.

The Bank of Korea (2016a), "Arbitraged Rates of Major Currencies Against Won, Longer Frequency, Average Rate" [Online] The Bank of Korea, Economic Statistics System, https://ecos.bok.or.kr/, 2016/2.

The Bank of Korea(2016b), "Visitor Arrivals by Month, 1975-2014" [Online], Korea Tourism Organization, https://kto. visitkorea.or.kr/kor/notice/data/statis.kto, 2016/2. 
Tuner, L. W., \& Witt, S. F. (2001). Factor influencing demand for international tourism: Tourism demand analysis using structural equation modeling, revisited. Tourism Management, 7, 21-38.

Uysal, M. (1998). The determinants of tourism demand: A theoretical perspectives. In I. loannides \& K. Debbage (Eds.), The economic geography of the tourist industry: A supply-side analysis. London: Routlege.

Witt, U. (2017). Capitalism as a complex adaptive system and its growth. JOltmC, 3, 12.

Witt, S. F., \& Moutinho, L. (1995). Tourism marketing and management handbook. Tourism Management, 16, 627-629.

Witt, S. F., \& Witt, C. A. (1995). Forecasting tourism demand: A review of empirical research. International Journal of Forecasting, 11(3), 447-475.

World Bank (2016a), "GDP, PPP (current international \$)" [Online] World Bank, International Comparison Program database. https://data.worldbank.org/, 2016/2.

World Bank (2016b), "Consumer price index $(2010=100)$ " [Online] International Monetary Fund, International Financial Statistics and data files. https://data.worldbank.org/, 2016/2

Yoo, C. K. (2012). Expenditures patterns by Korean wave event audiences and economic impact of direct spending on a Inchoen City. The Journal of the Korea Contents Association, 12(8), 399-410.

Yun, J. H. (2015). How do we conquer the growth limits of capitalism? Schumpeterian Dynamics of Open Innovation. JOltmC, 1, 17.

Yun, J. J., Yang, J., \& Park, K. (2016). Open innovation to business model: New perspective to connect between technology and market. Science, Technology, and Society, 21(3), 324-348.

Yun, J. J., Lee, D., Ahn, H., Park, K., \& Yigitcanlar, T. (2016). Not deep learning but autonomous learning of open innovation for sustainable artificial intelligence. Sustainability, 8(3), 797.

Submit your manuscript to a SpringerOpen ${ }^{\circ}$ journal and benefit from:

- Convenient online submission

- Rigorous peer review

- Open access: articles freely available online

- High visibility within the field

Retaining the copyright to your article

Submit your next manuscript at $>$ springeropen.com 